\title{
Design and Implementation of Wheelchair Controller Based Electroencephalogram Signal using Microcontroller
}

\author{
M.I. Arzak ${ }^{1}$, U. Sunarya ${ }^{2}$, S. Hadiyoso ${ }^{3}$ \\ ${ }^{1}$ School of Electrical Engineering, Telkom University, Bandung, Indonesia \\ ${ }^{2,3}$ Telkom Applied Science School, Telkom University, Bandung, Indonesia
}

\begin{tabular}{l} 
Article Info \\
\hline Article history: \\
Received Jun 06, 2016 \\
Revised Oct 25, 2016 \\
Accepted Nov 09, 2016 \\
\hline
\end{tabular}

Keyword:

Electroencephalogram

Fuzzy

Mind wave

PID

Wheelchairs

\begin{abstract}
Wheelchair is a medical device that can help patients, especially for persons with physical disabilities. In this research has designed a wheelchair that can be controlled using brain wave. Mind wave device is used as a sensor to capture brain waves. Fuzzy method is used to process data from mind wave. In the design was used a modified wheelchair (original wheelchair modified with addition de motor that can be control using microcontroller). After processing data from mindwave using fuzzy method, then microcontroller ordered dc motor to rotate. The dc motor connected to gear of wheelchair using chain. So when the dc motor rotated the wheelchair rotated as well. Controlling of DC motor used PID control method. Input encoder was used as feedback for PID control at each wheel. From the experimental results concentration level data of the human brain waves can be used to adjust the rate of speed of the wheelchair. The level accuracy of respons Fuzzy method ton system obtained by devides total true respons data with total tested data and the result is $85.71 \%$. Wheelchairs can run at a maximum speed of 31.5 $\mathrm{cm} / \mathrm{s}$ when the battery voltage is more than $24.05 \mathrm{~V}$. Moreover, the maximum load of wheelchair is $110 \mathrm{~kg}$.
\end{abstract}

Copyright (C) 2016 Institute of Advanced Engineering and Science. All rights reserved.

\section{Corresponding Author:}

S. Hadiyoso,

Telkom Applied Science School,

Telkom University,

Telekomunikasi Rd, Terusan Buah Batu,

Bandung-40257 Indonesia

Email: info@telkomuniversity.ac.id

\section{INTRODUCTION}

In this world there is a quadriplegic who was paralyzed in addition also has other shortcomings, such as the difficulty to move the motor nerves throughout the body which causes sometimes be very stiff, and had difficulty in speaking. The shortcomings make it difficult to control the wheelchair either manual or automatic. So to perform daily activities should be helped by someone. Not every time somebody can help, so we need a wheelchair that is controlled by the physically disabled are found lacking.

In this research, authors have made a wheelchair which is controlled using human brain signals (Electroencephalogram), where the human brain signal readings using mind wave module. The human brain signals will be used to control the speed and direction of the wheelchair. The related research are introduction of controlled wheelchair using BCI was performed using SSVEP feature [1], controlled wheelchair using asynchronous motor-imagery based BCI protocol [2], controlling a wheelchair indoors for a Myotrophic Lateral Sclerosis [3], coordinat control of an intelligent wheelchair based on BCI and speech recognition [4], BCI based real time control of wheelchair using EEG and WPT as feature extraction [5], Feature extraction for multi-class BCI using Canonical variates analysis [6].

Another study by Bhavna present EEG signal analysis using fractal dimension Higuchi to observe overall effect on brain. This analysis is used to determine the condition of the brain before and after chanting 
OM [7]. Related research by Hossain present EEG signal classification based on wavelet transform for feature extraction to determine right and left hand movements [8].

In this paper, we present a controlled wheelchair using single lead EEG module by neurosky based on concentration level of the mind (focus level) to determine the forward, right and left command. This system is also enabling speed control using a PID algorithm. The main contributions of this work are make an automatic wheelchair control use simple features and algorithm as well as the low cost of single lead EEG machines.

\section{BASIC THEORY}

\subsection{Electroencephalogram (EEG)}

Electroencephalogram is an instrument to capture the brain's electrical activity. The amplitude of EEG signal is very small and random. EEG itself is influenced by many variables, mental state, health, activity, recording environment, electrical interference from other organs, the external stimuli and age. The characteristics of EEG signal are generally non-stationary and random which add complexity in the processing of EEG signal. Classification of EEG signals in changing of certain variables can explain the activity of the brain and capture the changing on brain activity.

To simplify the classification of the EEG signal, it is needed transformation signal that identifies and quantifies the EEG signal spectrum. EG signals consisting of alpha waves (8-13) Hz with a conscious, closed eyes and relaxed conditions, beta waves (14-26) $\mathrm{Hz}$ often arise when conditions are thinking or activity, theta waves (4-7.5) Hz occurs when our circumstances being a light sleeper, sleepy or emotional system, and delta waves (0.5-4) Hz occurs when we are sleeping. In the research was used beta wave frequency because the beta signal often arised when conditions were thinking and activity. The feature of frequency band were level signal and average of amplitude. Therefore, the representation of the EEG signal in the frequency domain mostly done in research related to EEG signal analysis. Figure 1 is an example of the EEG signal [9].

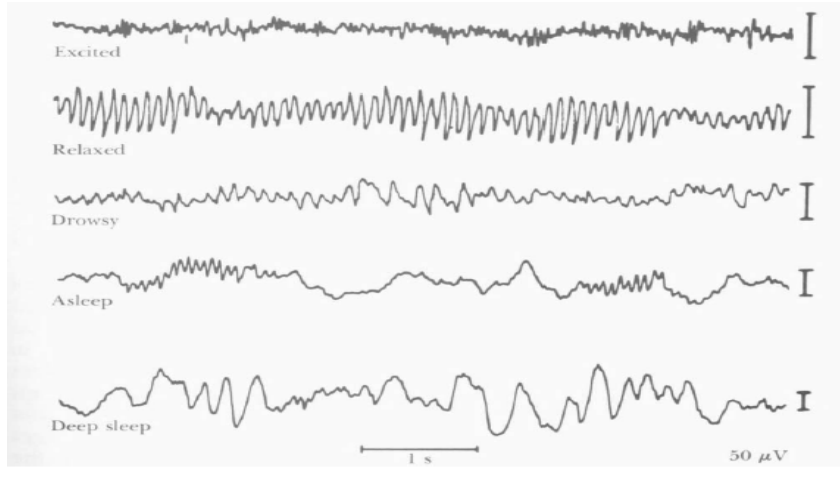

Figure 1. Sample EEG Signal [9]

\subsection{Midwave Neurosky}

Neuro Sky Mindwave is module for EEG acquisition based on single lead electrode. Therefore it only generated one signal EEG. Neuro Sky Mindwave used to read EEG signal waveform. Where this device can communicate with other devices such as computer, laptop, and microcontroller via a wireless network (Bluetooth). The shape of the mobile mindwavecan be seen in Figure 2

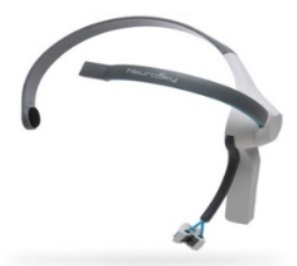

Figure 2. Mindwave Neuro Sky 
Specifications

a. Weighs $90 \mathrm{~g}$

b. Sensor arm up: Height: $225 \mathrm{~mm}$ x Width:155mm x Depth: $92 \mathrm{~mm}$

c. Sensor Arm down: height: $225 \mathrm{~mm} x$ width: $155 \mathrm{~mm}$ x depth: $165 \mathrm{~mm}$

d. $30 \mathrm{~mW}$ rate power; $50 \mathrm{~mW}$ max power

e. $2.420-2.471 \mathrm{GHz}$ RF frequency

f. $6 \mathrm{dBm}$ RF max power

g. $250 \mathrm{kbit} / \mathrm{s} \mathrm{RF}$ data rate

h. $10 \mathrm{~m}$ RF range

i. $\quad 5 \%$ packet loss of bytes via wireless

j. $\quad$ UART Baudrate: 57,600 Baud

k. $1 \mathrm{mV}$ pk-pk EEG maximum signal input range

1. $3 \mathrm{~Hz}-100 \mathrm{~Hz}$ hardware filter range

m. 12 bits $\mathrm{ADC}$ resultion

n. $512 \mathrm{~Hz}$ sampling rate

o. $1 \mathrm{~Hz}$ eSense calculation rate

Measurements:

a. Raw signal

b. Neuroscience defined EEG power spectrum (Alpha, Beta, Tetha, Delta, Gamma)

c. eSense meter for Attention

d. eSense meter for Meditation

e. eSense Blink Detection

f. On-head detection

\subsection{PID (Proporsional, Integral, Derivatif)}

PID (Proportional, Integral, Derivative) is a controller that has functions to process the error signal into a control signal with feedback's characteristics to get the precision of the system. PID consists of three types of components, namely proportional, integral, and derivative. These three types of components can be used together or individually in accordance with the desired response in a system.

PID control is a combination of proportional, integral, and derivative. This controller has the advantage of another type of controller due to its characteristics is a combination of controllers P, PI controller, and PID controllers. PID control relationships can be expressed in the following equation.

$$
u(t)=K p \cdot e(t)+K p T d \frac{d e(t)}{d t}+\frac{K p}{T i} \int_{0}^{t} e(t) d t u(t)=K p \cdot e(t)+K i \int e(t) d t+K d \frac{d e(t)}{d t}
$$

or another equation using transfer function

$$
\begin{aligned}
& U(s)=K p\left(1+T d s+\frac{1}{T i s}\right) \\
& U(s)=\left(K p+K d s+\frac{K i}{s}\right)
\end{aligned}
$$

PID control is described in the following block diagram as shown in Figure 3.

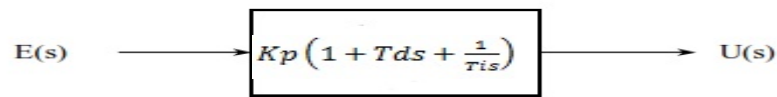

Figure 3. Block Diagram PID Controller

\subsection{Fuzzy Logic}

Fuzzy logic method first introduced by Lotfi A. Zadeh, that has a degree of membership in a range of 0 (zero) to 1 (one), in contrast to digital logic that has only two values: 1 (one) or 0 (zero). Fuzzy logic is used to translate a quantity that is expressed using linguistic. 


\section{RESEARCH METHOD}

\subsection{System Design}

In designing this automatic wheelchair is includes hardware and software design. The system uses mobile mind wave as input device to reads the EEG signal. Then the computer is used to process the Raw EEG signal and user interface. Previous research about processing and spectral analysis of the raw EEG signal from the mind wave [10].

Signals EEG from mobile mind wave sent to a computer and in the computer was desaigned application that could filter beta frequency from others frequency (level signal and average of amplitude beta frequency) which is then passed to the microcontroller. Microcontroller type that used is STM32F4 the main controller. Level signal and average of amplitude then used as input of fuzzy method (inside of microcontroller) to classify. The result of classifying was decision to move dc motor (turn left, turn right or straight forward). In the research PD was used for controlling speed of dc motor.

This microcontroller is used as the main controller which functions to regulate the rate of the wheelchair. On the output side there are 2 pieces of microcontroller dc motor driver is connected to the actuator wheelchair. DC motors are used as actuators of wheelchair. This wheelchair is equipped with an encoder as sensor to calculate the number of turns on each wheel. This sensor is used as feedback to the microcontroller so that the rate of wheelchair becomes smooth.

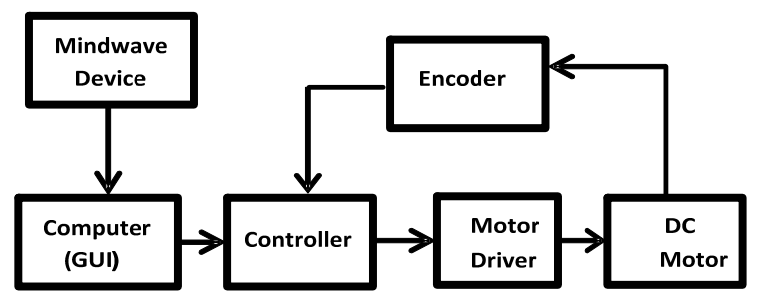

Figure 4. System Design

\subsection{Design of Wheelchair}

Wheelchair has size $102 \mathrm{~cm}$ x $61 \mathrm{~cm} \mathrm{x} 83 \mathrm{~cm}$ of (length x width $\mathrm{x}$ height). Planning robot wheelchair mechanics done by modifying the existing manual wheelchair. Then the encoder mounted directly to the axle. Comparing gear ratio motor with wheels is $1: 3$. Specification of wheelchair is shown in Table 1 and wheelchair design is shown in Figure 5.

System in the robot's motion using differential wheel system, which has two-wheel which differential free wheel can move forward or backward. Since each wheel driven by a DC motor.

Table 1. Specification of Wheelchair

\begin{tabular}{ll}
\hline Dimension of Robot & $102 \mathrm{~cm} \times 61 \mathrm{~cm} \times 83 \mathrm{~cm}$ \\
Controller & STM32F4Discovery \\
Maximum of Speed & $30 \mathrm{~cm} / \mathrm{s}$ \\
Voltage & Accumulator 24 Volt \\
Mobile System & Differential Wheel \\
Actuator & DC Motor 24 Volt \\
Ratio of Gear Motor : wheel & $1: 3$ \\
Maximum Load & $120 \mathrm{~kg}$ \\
\hline
\end{tabular}

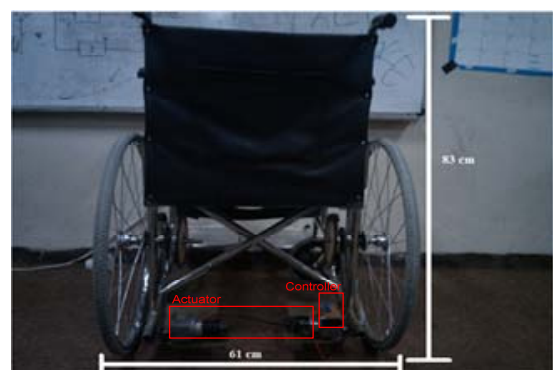

Figure 5. Wheelchair Design 


\subsection{Fuzzy Logic Design}

The controls are used on robotic wheelchair is fuzzy logic control. In research previously is used LDA as classification method [11] and wheelchair with EEG [12]. EEG and eye-blinking signals [13], and gesture recognition for automatic wheelchair [14]. In this system, the mobile will transmit data mind wave level of focus and a person's brain wave data The level data is obtained using trial and error.In the experiment user tries to think go straight, turn left, turn right, and stop then the level signal can be seen on the application on the computer. From the experiment the user can make decision to make the limit data as level of every signal brain wave. Data level of focus and brain wave data is what will be the input to the fuzzy logic. The output of this system form speed drive motor on each wheel chair. The output of the system in the form of a robot velocity obtained from a given PWM DC motor. Fuzzy logic flowchart is shown in Figure 6.

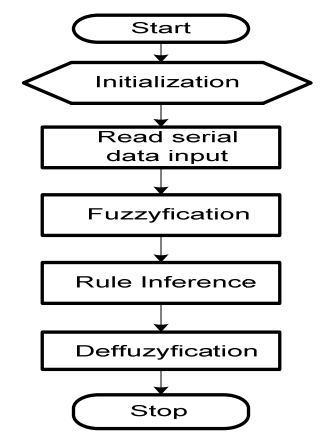

Figure 6. Fuzzy Logic Flowchart

\subsubsection{Fuzzyfication}

Data level of focus and brain wave data transmitted by the mobile mind wave received by a computer or PC. The data is then processed in the Fuzzyfication the process of changing the value of the sensor output data (crisp inputs) into the form of fuzzy sets according to the membership function. In the research used two inputs as membership function of fuzzy they are level concentration amplitude Figure 7 and average of amplitude Figure 8. Membership of motor output is shown in Figure 9.

As for the brain wave data input has 3 linguistic values, namely Low, Medium, High trapezoid membership functions. Membership functions can be seen in the picture.

In this work, the output system is using Fuzzy Sugeno models. The output of this system is made there are two that right DC motor speed and left DC motor speed. For the system output in the form of speed has 7 linguistic values: slowest, slower, slow, normal, fast, faster, fastest. Membership of Motor Output

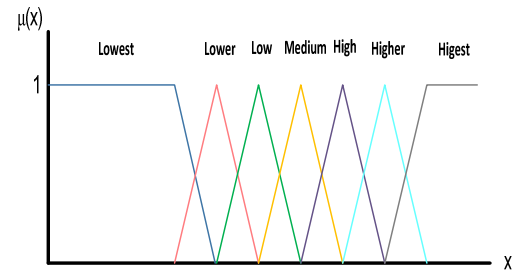

$\begin{array}{lllllll}30 & 40 & 50 & 60 & 70 & 80 & 90\end{array}$

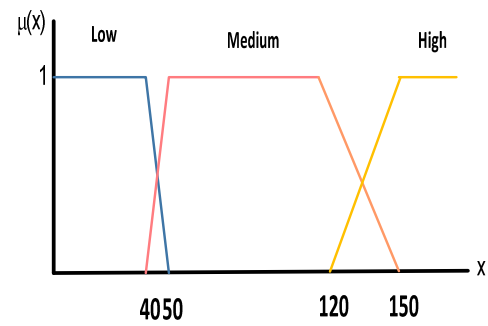

Figure 8. Membership Function of Average Brainwaves

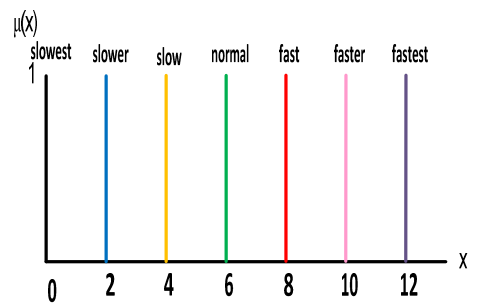

Figure 9. Membership of Motor Output

\subsubsection{Deffuzyfication}

The final step is deffuzification, mapping the fuzzy output values generated at this stage to the inference rules quantitative output values. In designing this wheelchair robot deffuzification process Weight Average method and the output of the process deffuzification form on any DC motor speed. 


\subsection{PID Controller}

In this scheme PD is used as a controller for controlling the speed of a DC motor to a wheel chair. $\mathrm{PD}$ controller is represented by equation (4 and 5). Where this control will determine the output of the PWM to be provided to the DC motor. Feedback for PD control is obtained from the rotary encoder sensor. Medota trial error is used to get the valueof $\mathrm{kp}$ and $\mathrm{kd}$ effective when implanted into the system.

$$
u(t)=K p \cdot e(t)+K p T d \frac{d e(t)}{d t}
$$

or another equation using transfer function:

$$
\frac{U(s)}{E(s)}=K p(1+T d s)
$$

\subsection{Software Design}

Features included in software applications such as:

a. Features mindwave communication between computerwith mobile and microcontroller. A feature that can connect computer with communication between controller wheelchair and computer with mobile mindwave.

b. Features to display graphics in real time EEG signal.

c. Feature to show the direction of the wheelchair based on EEG signal conditions.

GUI design of the software can be seen in Figure 10.

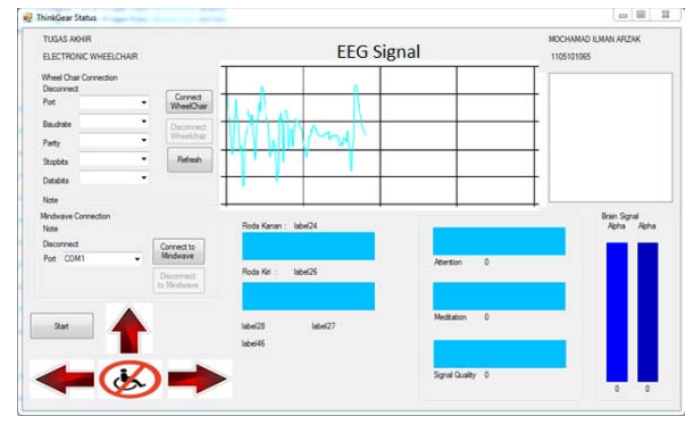

Figure 10. GUI Design

\section{RESULTS AND ANALYSIS}

To run the wheelchair control is based on information the concentration level through EEG signal. The data of concentration level is obtained from the device mindwave that showing the level concentration of user. The concentration level is represented by a value between $0-100$. 0 is the current conditions do not concentrate while 100 is the current state of being full concentration.

Testing is done repeatedly for one week. Based on the test data can be analyzed that the precision of the use of fuzzy logic. True respons means when user intented to turn left, turn right, straight forward or stop then sistem answer as request and tested data means from all testing or experiment that was done. Testing data equals to true respons plus false respons.

The precision of the use of fuzzy logic $=\frac{\sum \text { true respons }}{\sum \text { testing data }} \times 100 \%=85.71 \%$

Concentration level is obtained from EEG signal that is captured from Neurosky brainwave modul and then it is transmitted to application on computer to be representated as its level. From the Table 2, Table 3, and Table 4 can be seen that as the greater value of combination of level concentration and brainwave signal so it can be made difference easly between the action wheelchait to move forward, turn left, and turn right.

Based on the experimental results on a wheelchair, the wheelchair has a value of KP and KD are different at each set point. A value per second of the rotary pulse encoder is used as feedback for the PID control. From the Table 5 showed that for getting PWM value of both right wheel and left wheel used different value of KP (Proportional Constant) and KD (Deripative Constant) for every set point (SP) to be stable. The value of KP and KD was obtained by trial and error until stable condition. 
Table 2. Response of Wheelchair when Forward Command

\begin{tabular}{|c|c|c|c|c|c|}
\hline No & Level concentration & Brainwave & $\begin{array}{l}\text { Speed Wheel Right } \\
(\mathrm{m} / \mathrm{s})\end{array}$ & $\begin{array}{l}\text { SpeedWheel } \\
\text { Left }(\mathrm{m} / \mathrm{s})\end{array}$ & Respons \\
\hline 1 & 10 & 35 & 0 & 0 & Stop \\
\hline 2 & 18 & 30 & 0 & 0 & Stop \\
\hline 3 & 37 & 32 & 3.4 & 3.4 & Straight \\
\hline 4 & 20 & 29 & 0 & 0 & Stop \\
\hline 5 & 48 & 22 & 5.6 & 5.6 & Straight \\
\hline 6 & 55 & 35 & 7 & 7 & Straight \\
\hline 7 & 68 & 38 & 9.6 & 9.6 & Straight \\
\hline 8 & 71 & 40 & 10 & 10 & Straight \\
\hline 9 & 85 & 15 & 12 & 12 & Straight \\
\hline 10 & 98 & 26 & 12 & 12 & straight \\
\hline 11 & 100 & 20 & 12 & 12 & straight \\
\hline 12 & 100 & 18 & 12 & 12 & straight \\
\hline 13 & 90 & 29 & 12 & 12 & straight \\
\hline 14 & 95 & 33 & 12 & 12 & straight \\
\hline 15 & 51 & 34 & 6.2 & 6.2 & straight \\
\hline 16 & 45 & 38 & 5 & 5 & straight \\
\hline 17 & 40 & 40 & 4 & 4 & straight \\
\hline 18 & 30 & 29 & 2 & 2 & straight \\
\hline 19 & 85 & 30 & 12 & 12 & straight \\
\hline 20 & 23 & 36 & 0.6 & 0.6 & stop \\
\hline 21 & 38 & 37 & 3.6 & 3.6 & stop \\
\hline
\end{tabular}

Table 3. Response of Wheelchair when Turn Right Command

\begin{tabular}{|c|c|c|c|c|c|}
\hline No & Level concentration & Brainwave & $\begin{array}{l}\text { Wheel } \\
\text { Right }\end{array}$ & $\begin{array}{c}\text { Wheel } \\
\text { Left }\end{array}$ & Respons \\
\hline 1 & 24 & 55 & 0.6 & 0.8 & Right \\
\hline 2 & 65 & 68 & 5 & 9 & Right \\
\hline 3 & 85 & 78 & 8 & 12 & Right \\
\hline 4 & 92 & 125 & 8 & 12 & Right \\
\hline 5 & 87 & 130 & 8 & 12 & Right \\
\hline 6 & 33 & 99 & 0 & 2.6 & Right \\
\hline 7 & 45 & 62 & 1 & 5 & Right \\
\hline 8 & 67 & 78 & 5.4 & 9.4 & Right \\
\hline 9 & 87 & 56 & 8.8 & 12 & Right \\
\hline 10 & 45 & 145 & 3.7 & 2.3 & Left \\
\hline 11 & 55 & 38 & 7 & 7 & Straight \\
\hline 12 & 53 & 64 & 2.6 & 6.6 & Right \\
\hline 13 & 50 & 95 & 2 & 6 & Right \\
\hline 14 & 84 & 71 & 8 & 12 & Right \\
\hline 15 & 67 & 155 & 9.4 & 5.4 & Left \\
\hline 16 & 66 & 47 & 7.5 & 9.2 & Right \\
\hline 17 & 32 & 52 & 1.3 & 2.5 & Right \\
\hline 18 & 21 & 55 & 0.2 & 0.2 & Straight \\
\hline 19 & 33 & 68 & 0 & 2.6 & Right \\
\hline 20 & 34 & 65 & 0 & 2.8 & Right \\
\hline 21 & 45 & 89 & 1 & 5 & Right \\
\hline
\end{tabular}


Table 4. Response of Wheelchair when Turn Left Command

\begin{tabular}{cccccc}
\hline No & Level concentration & Brainwave & Wheel Right & Wheel Left & Respons \\
\hline 1 & 100 & 250 & 12 & 8 & Left \\
2 & 89 & 159 & 12 & 8 & Left \\
3 & 55 & 157 & 7 & 3 & Left \\
4 & 48 & 110 & 1.6 & 5.6 & Right \\
5 & 78 & 132 & 8.2 & 11 & Right \\
6 & 45 & 157 & 5 & 1 & Left \\
7 & 64 & 168 & 8.8 & 4.8 & Left \\
8 & 57 & 755 & 7.4 & 3.4 & Left \\
9 & 59 & 498 & 7.8 & 3.8 & Left \\
10 & 66 & 569 & 9.2 & 5.2 & Left \\
11 & 75 & 357 & 11 & 7 & Left \\
12 & 98 & 299 & 12 & 8 & Left \\
13 & 59 & 200 & 7.8 & 3.8 & Left \\
14 & 48 & 268 & 5.6 & 1.6 & Left \\
15 & 49 & 127 & 1.8 & 5.8 & Right \\
16 & 59 & 100 & 3.8 & 7.8 & Right \\
17 & 67 & 99 & 5.4 & 9.4 & Right \\
18 & 88 & 357 & 12 & 8 & Left \\
19 & 90 & 458 & 12 & 8 & Left \\
20 & 100 & 257 & 12 & 8 & Left \\
21 & 89 & 225 & 12 & 8 & Left \\
\hline
\end{tabular}

Table 5. Result of PD Controller

\begin{tabular}{ccccccc}
\hline SET & \multicolumn{3}{c}{ Right Wheel } & \multicolumn{3}{c}{ Left Wheel } \\
POINT & Value PWM & KP & KD & Value PWM & KP & KD \\
\hline SP 1 & 100 & 1 & 30 & 100 & 1 & 30 \\
SP 2 & 200 & 1 & 30 & 200 & 1 & 30 \\
SP 3 & 325 & 2 & 40 & 325 & 2 & 40 \\
SP 4 & 450 & 3 & 100 & 450 & 3 & 100 \\
SP 5 & 600 & 5 & 50 & 600 & 5 & 50 \\
SP 6 & 800 & 6 & 70 & 800 & 6 & 70 \\
\hline
\end{tabular}

\section{CONCLUSION}

Based on testing, the wheelchair able to move well. If we increase our level of concentration of the wheelchair speed will also increase. For the moment we are commanded to turn right or turn left wheelchair can then execute the command properly. Fuzzy logic used to work well. Fuzzy logic that consists of 21 rule based data input concentration and brain waves from mind wave that produces output on each DC motor speed has $85.71 \%$ accuracy. Using of filter should be implemented; it is intended to minimize noise on the brain wave data. To minimize noise data from the EEG waves will be more accurate and simplify the process of data analysis.

Using EEG sensors that have more than one channel electrode, this can be used as a standard for data obtained more accurately. The use of more than one channel makes it possible to detect the imagination of the human brain

\section{REFERENCES}

[1] Singla, R., B.A. Haseena. 2013. BCI based wheelchair control using steady state visual evoked potentials and support vector machines. Internasional Journal of Soft Computing and Engineering (IJSCE), Volume 3, Issue 3, July 2013

[2] Carlson, T., Millan, Jose del R. 2013. Brain-controlled wheelchairs a robotic architecture. IEEE robotics and automation magazine. 20(1): 65-73, March 2013. DOI: 10.1109/MRA.2012.2229936

[3] Rebsamen, Brice et.al. 2008. Interacting with autonomy "Controlling a wheelchair indoors using thought". IEEE Intelligent Systems. IEEE Computer Society, 1541-1672/07

[4] Wang, Hong-tao, Li, Yuan-qing, Yu, Tian-you. 2014. Coordinated control of an intelligent wheelchair based on a brain-computer interface and speech recognition. Journal of Zhejiang University-SCIENCE C (Computers \& Electron), 2014; 15(10): 832-838

[5] Khare, V., Santhosh, J., Anand, S., Bhatia, M.2011. Brain computer interface based real time control of wheelchair using electroencephalogram. International Journal of Soft Computing and Engineering (IJSCE), Volume 1, Issue 5, November 2011.

[6] Galan, Ferran et.al. Feature extraction for Multi-class BCI using canonical variates Analysis. Intelligent Signal Processing. IEEE International Symposium. E-ISBN: 978-1-4244-0830-6 Print-ISBN: 978-1-4244-0830-6 INSPEC Accession Number : 9825141

[7] Bhavna P. Harne. 2014. Higuchi Fractal Dimension Analysis of EEG Signal before and after OM Chanting to 
Observe Overall Effect on Brain. International Journal of Electrical and Computer Engineering (IJECE). Vol. 4, No. 4, August 2014, pp. 585-592.

[8] A.B.M. Aowlad Hossain, Md. Wasiur Rahman, Manjurul Ahsan Riheen. 2015. Left and Right Hand Movements EEG Signals Classification Using Wavelet Transform and Probabilistic Neural Network. International Journal of Electrical and Computer Engineering (IJECE). Vol. 5, No. 1, February 2015, pp. 92-101.

[9] J. G. Webster. 1999. Medical Instrumentation: Application and Design/Wiley, Singapore.

[10] Sałabun, Wojciech. 2014. Processing and spectral analysis of the raw EEG signal from The Mind Wave. Przeglad Elektrotechniczny, ISSN 0033-2097, R. 90 NR 2/2014:169-173.

[11] F. Gallan et.al. 2008. A brain-actuated wheelchair: Asynchronous and non-invasive brain-computer interfaces for continuous control of robots. Clinical Neurophysiology, 119 (2008) 2159-2169.

[12] Khare, Vijay. 2010. Controlling Wheelchair using electroencephalogram. International Journal of Computer Science and Information Security (IJCSIS). Vol. 8, No.2, 2010: 181-187.

[13] Lin, Jzau-Sheng \& Yang, Win-Ching.2012. Wireless brain-computer interface for electric wheelchairs with EEG and eye-blinking signals. International Journal of Innovative Computing, International and Control, Vol. 8, No. 9. ICIC International ISSN 1349-4198 pp. 6011-6024

[14] Paulose, Smitha et.al. 2014. Automatic wheelchair using gesture recognition along with room automation. Transactions on Engineering and Sciences, Vol. 2, Issue 5, ISSN: 2347-1964 Online 2347-1875 Print.

\section{BIOGRAPHIES OF AUTHORS}

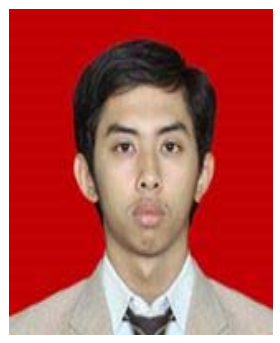

Mochamad Ilman Arzak received the Bachelor Degree of Electrical Engineering from Telkom University, Bandung, Indonesia in November 2014. He joined Electronics and Intelligence Robotic Research Group (EIRRG) from 2011 -2014 in Telkom Univesity. His research interests are embedded system andRobotics.

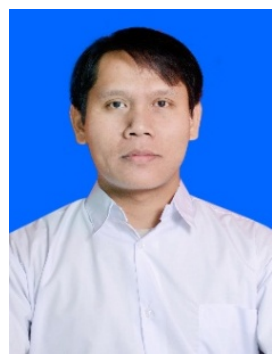

Unang Sunarya received the Master Degree of Electrical Telecommunication Engineering from Telkom University, Bandung, Indonesia in February 2012. He joined as a Lecturer in the department of Electronics and Communication Engineering of Telkom University, in 2010. Supervisor of Electronics and Intelligence Robotic Research Group (EIRRG) from 2010 -2015 in Telkom Univesity. His research interests are wireless sensor network, embedded system, Robotics, and Signal Processing.

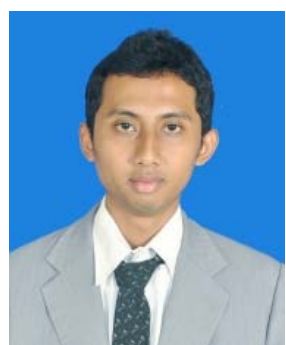

Sugondo Hadiyoso received the Master.in Electrical-Telecommunication Engineering from Telkom University, Bandung, Indonesia in March 2012. He joined as a Lecturer in the department of Electronics and Communication Engineering of Telkom University, in 2010. Where he is currently members of Biomedical Instrumentation Research Group in Telkom Univesity. His research interests are wireless sensor network, embedded system, logic design on FPGA and biomedical engineering. 